\title{
Eosinophilic oesophagitis in children: an uncommon occurrence in a predominantly Chinese population in Singapore
}

\author{
Li Nien Michelle $\underline{\operatorname{Tan}}^{1}$, MBBS, MRCPCH, Supriya Srivastava ${ }^{2}$, MD, Ming $\underline{T e h}^{3}$, FRCPA, FRCPath, Seng Hock $\underline{\text { Quak }}{ }^{1,4}$, MMed, FRCPCH,
} Marion $M A w^{1,4}$, MBBS, MMed

INTRODUCTION We aimed to determine the prevalence and clinical manifestations of eosinophilic oesophagitis (EoE) in children who presented to a tertiary care hospital in Singapore.

METHODS We conducted a retrospective review of all oesophageal biopsies taken during oesophagogastroduodenoscopy (OGD) from March 2010 to December 2011. The patients' demographics and clinical characteristics were collected. Biopsies were reviewed by a single pathologist who was blinded to the original reports, using the current consensus criteria for the histological diagnosis of EoE.

RESULTS Of the 88 children who had biopsies during OGD, 4 (4.5\%) children (three boys, one girl; three Chinese, one Caucasian) were diagnosed with EoE. Their median age was 9.5 (range 4.0-12.0) years. The main clinical presentations were abdominal pain (in the three older children) and vomiting (in the youngest child). Three children had a history of atopy. Three children were diagnosed with EoE in the original histology reports, while one was diagnosed after the second review following histology demonstrating > 15 eosinophil granulocytes per high power field and microabscess formation. Endoscopy findings revealed oesophagitis in two children, one of whom was already on acid suppression therapy. Although three children were started on acid suppression therapy, they continued to be symptomatic. One child was also treated with swallowed fluticasone and two with food allergen avoidance, resulting in symptom improvement. CONCLUSION Although EoE is uncommon in Singapore, greater awareness is needed among family physicians and general paediatricians. Paediatric gastroenterologists should alert pathologists when sending biopsy specimens that are suspicious for EoE.

Keywords: biopsies, children, eosinophilic oesophagitis, oesophagogastroduodenoscopy

\section{INTRODUCTION}

Eosinophilic oesophagitis (EoE) was first reported in 1978 by Landres et al, ${ }^{(1)}$ but it was only considered to be a separate entity from oesophageal inflammation due to gastro-oesophageal reflux in 1990. EoE is a clinicopathologic condition that involves eosinophilic inflammation of the oesophagus and is associated with clinical manifestations related to oesophageal dysfunction. The disease has become increasingly prevalent since the last decade; ${ }^{(2-4)}$ in fact, there was a fourfold increase in the incidence of EoE among children aged below 19 years between 2000 and 2003. ${ }^{(2)}$ This has caught the attention of many paediatricians worldwide. However, while EoE is a well-recognised disease in the West, there is little epidemiological data on EoE from nonWestern countries, such as China, Korea and Saudi Arabia. ${ }^{(5-7)}$

The diagnosis of EoE is predominantly dependent on the patient's clinical presentation, and the endoscopic and histologic findings of mucosal biopsies taken from the oesophagus. Although eosinophil count is used in EoE diagnosis, it is not considered to be the gold standard for EoE diagnosis..$^{(8-11)}$ This is because children with an eosinophil count $<9$ per high power field (hpf) may not have EoE. Instead, such eosinophil counts may be due to other causes of eosinophilia in the oesophageal mucosa, such as gastro-oesophageal reflux disease (GERD). Additionally, there have been reports of difficulty in differentiating EoE from GERD in adults when eosinophil counts are $>20 /$ hpf. $^{(12,13)}$

Several studies have described the endoscopic features of EoE in children diagnosed with the condition. ${ }^{(11,14,15)}$ However, those endoscopic features are often subtle and easy to miss. Additionally, even though EoE is thought to be common among Caucasians, a high index of suspicion is recommended regardless of the ethnicity or gender of the patient, so that adequate oesophageal biopsies can be obtained during endoscopy to ensure an accurate diagnosis..$^{(11,14,15)}$

There is a lack of detailed paediatric epidemiological data from several parts of the world, including Singapore. We thus aimed to determine the frequency and clinical manifestations of EoE in children who presented to a paediatric unit in Singapore.

\section{METHODS}

We performed a retrospective review of oesophageal biopsies taken during oesophagogastroduodenoscopies (OGDs) that were conducted in the paediatric unit of Khoo Teck Puat National University Children's Medical Institute, a tertiary university hospital located in western Singapore. Approval from our institution's Ethics Review Board was obtained prior

${ }^{1}$ Khoo Teck Puat - National University Children's Medical Institute, National University Health System, ${ }^{2}$ Cancer Science Institute of Singapore, National University of Singapore, ${ }^{3}$ Department of Pathology, National University Health System, ${ }^{4}$ Department of Paediatrics, Yong Loo Lin School of Medicine, National University of Singapore, Singapore Correspondence: Dr Tan Li Nien Michelle, Associate Consultant, Khoo Teck Puat - National University Children's Medical Institute, National University Health System, 1E Kent Ridge Road, NUHS Tower Block Level 12, Singapore 119228. michelle_In_tan@nuhs.edu.sg 
to the review, analysis and compilation of data. The intention was to review 100 biopsy specimens, working backwards from December 2011. However, only 90 oesophageal biopsy specimens, dating back to March 2010, were eventually reviewed in the present study. We were not able to include more specimens due to missing or incomplete data, and difficulty in accessing data recorded prior to March 2010. These 90 biopsies had previously been reviewed by various pathologists according to the 2007 recommendations, ${ }^{(12)}$ which were primarily based on an eosinophil count of $15 / \mathrm{hpf}$ at the point when the OGD was performed.

For the purpose of the present study, a single pathologist reviewed all 90 biopsy specimens again. This pathologist was blinded to the original histology report and reviewed the specimens using the current consensus criteria for the histological diagnosis of EoE. ${ }^{(16)}$ Based on the current consensus guidelines, EoE is present pathologically when $\geq 1$ biopsy specimens show eosinophil-predominant inflammation and a minimum of 15 eosinophils/hpf. ${ }^{(16)}$ In addition to the histological criteria, the 2011 guidelines also emphasise the clinical symptom of oesophageal dysfunction and the exclusion of other causes of oesophageal eosinophilia for the diagnosis of EoE.

In this retrospective case series, the medical records of the patients (including their clinical records, discharge summaries, laboratory results and endoscopy reports) were analysed. The clinical records and discharge summaries were either documented or vetted by the rotating paediatric gastroenterology registrar or the consultant gastroenterologist who attended to the patient. The variables studied included the child's age, gender, clinical symptom(s), indication(s) for OGD, histopathology based on the initial and second review, and allergic or atopic symptoms, as well as the treatment instituted after a diagnosis of EoE was made.

\section{RESULTS}

A total of 90 oesophageal biopsies were taken during the 237 OGDs performed in the paediatric population of our hospital from March 2010 to December 2011. Oesophageal biopsies were not taken if the OGDs were performed for variceal bleed or screening, foreign body removal and gastrostomy feeding tube insertion. However, during the second review, the pathologist could only review 88 biopsies, as the original biopsy tissue sample of one patient was too small to be assessed and another patient was erroneously included twice in the list generated from the hospital's database.

The mean age of the 88 patients was nine years (range 8 months -37 years) and 49 of them were male. The reasons for OGD included abdominal pain $(n=45)$, vomiting with/without gastro-oesophageal reflux symptoms $(\mathrm{n}=33)$, anaemia with/ without gastrointestinal bleed ( $\mathrm{n}=8$ ), suspected inflammatory bowel disease $(n=8)$, suspected coeliac disease $(n=2)$ and surveillance for previously known EoE $(n=1)$.

In the second review of the biopsy specimens, EoE was diagnosed in four of the $88(4.5 \%)$ children. The characteristics of the four patients who were diagnosed with eosinophilic oesophagitis (EoE) at the second review are shown in Table I. During the first review of the biopsy specimens (i.e. the original histology report), three of the four children had already been diagnosed with EoE (Patients 2, 3 \& 4), while the fourth child (Patient 1) had been diagnosed with GERD. During the second review, Patient 1's biopsy specimen demonstrated oesophageal

Table I. Characteristics of the four patients who were diagnosed with eosinophilic oesophagitis (EoE) in the second review.

\begin{tabular}{|c|c|c|c|c|c|c|c|}
\hline No. & $\begin{array}{l}\text { Gender, ethnicity, } \\
\text { age at OGD/ } \\
\text { symptom onset (yr) }\end{array}$ & $\begin{array}{l}\text { History } \\
\text { of atopy }\end{array}$ & $\begin{array}{l}\text { Clinical } \\
\text { diagnosis }\end{array}$ & $\begin{array}{l}\text { Reason } \\
\text { for OGD }\end{array}$ & OGD findings & $\begin{array}{l}\text { Eosinophils/ } \\
\text { hpf at } 2 \text { nd } \\
\text { review }\end{array}$ & $\begin{array}{l}\text { Treatment based } \\
\text { on original } \\
\text { histology }\end{array}$ \\
\hline 1 & $\begin{array}{l}\text { Male, Chinese, } \\
4 / 2\end{array}$ & Present & GERD & $\begin{array}{l}\text { Recurrent } \\
\text { vomiting }\end{array}$ & $\begin{array}{l}\text { Oesophagitis - } \\
\text { the mid-to-lower } \\
\text { oesophagus had } \\
\text { both a granular } \\
\text { and erythematous } \\
\text { appearance }\end{array}$ & 17 & $\begin{array}{l}\text { Omeprazole, } \\
\text { domperidone }\end{array}$ \\
\hline 2 & $\begin{array}{l}\text { Male, Chinese, } \\
10 / 10\end{array}$ & Present & Gastritis & Abdominal pain & $\begin{array}{l}\text { Lax lower } \\
\text { oesophageal } \\
\text { sphincter, normal } \\
\text { macroscopic } \\
\text { appearance of the } \\
\text { oesophagus and } \\
\text { antrum }\end{array}$ & 30 & $\begin{array}{l}\text { Omeprazole, } \\
\text { food avoidance }\end{array}$ \\
\hline 3 & $\begin{array}{l}\text { Female, Chinese, } \\
9 / 8\end{array}$ & Absent & $\begin{array}{l}\text { H. pylori- } \\
\text { associated } \\
\text { gastritis }\end{array}$ & $\begin{array}{l}\text { Abdominal pain, } \\
\text { lack of response } \\
\text { to previous } \\
\text { courses of triple } \\
\text { therapy }\end{array}$ & $\begin{array}{l}\text { Duodenal ulcer, } \\
\text { erosive gastritis }\end{array}$ & 32 & $\begin{array}{l}\text { Quadruple } \\
\text { therapy for } \\
\text { H. pylori and } \\
\text { food avoidance }\end{array}$ \\
\hline 4 & $\begin{array}{l}\text { Male, Caucasian, } \\
12 / 9\end{array}$ & Present & $\begin{array}{l}\text { EoE* } \\
\text { coeliac } \\
\text { disease }\end{array}$ & $\begin{array}{l}\text { Surveillance for } \\
\text { known EoE }\end{array}$ & $\begin{array}{l}\text { Oesophagitis - } \\
\text { inflammation and } \\
\text { slough were seen } \\
\text { at the mid-to- } \\
\text { lower oesophagus }\end{array}$ & 26 & $\begin{array}{l}\text { Food avoidance, } \\
\text { swallowed } \\
\text { fluticasone }\end{array}$ \\
\hline
\end{tabular}

*Known case. GERD: gastro-oesophageal reflux disease; H. pylori: Helicobacter pylori; hpf: high power field; OGD: oesophagogastroduodenoscopy 

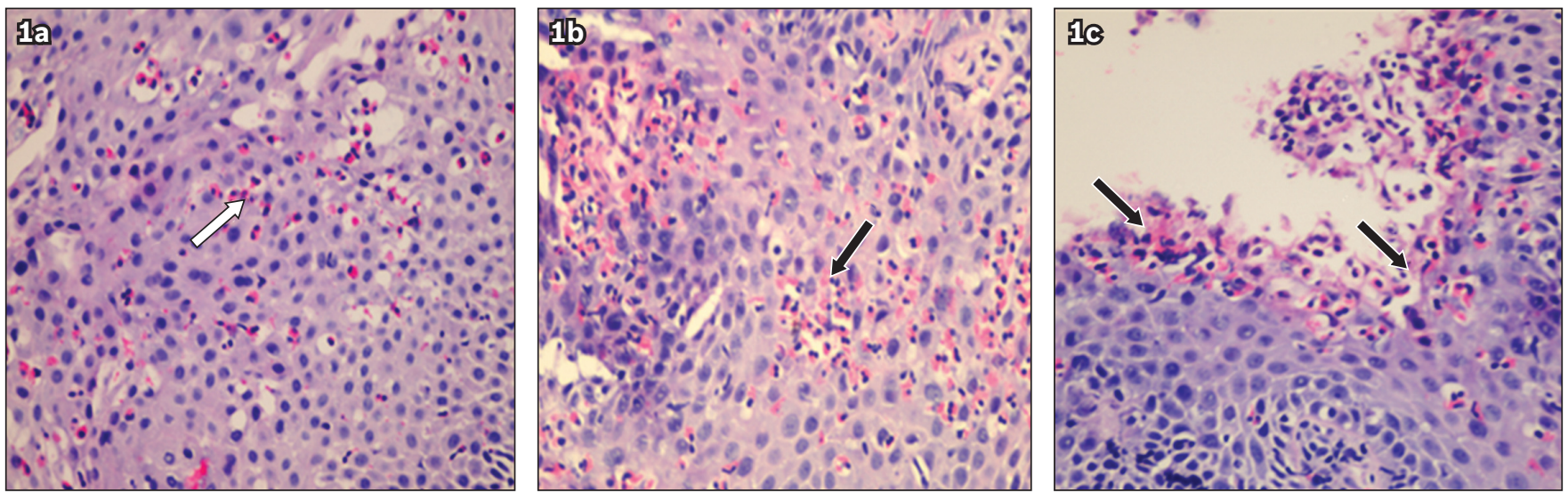

Fig. 1 Photomicrographs show (a) patchy distribution of eosinophils (white arrow) in the oesophageal squamous epithelium; (b) a collection of 15-20 eosinophils (black arrow), in which a few eosinophils are degranulated; and (c) superficial collections of $\geq 4$ eosinophils (black arrows) on the surface of the squamous epithelium (all haematoxylin \& eosin, $\times 400$ ).
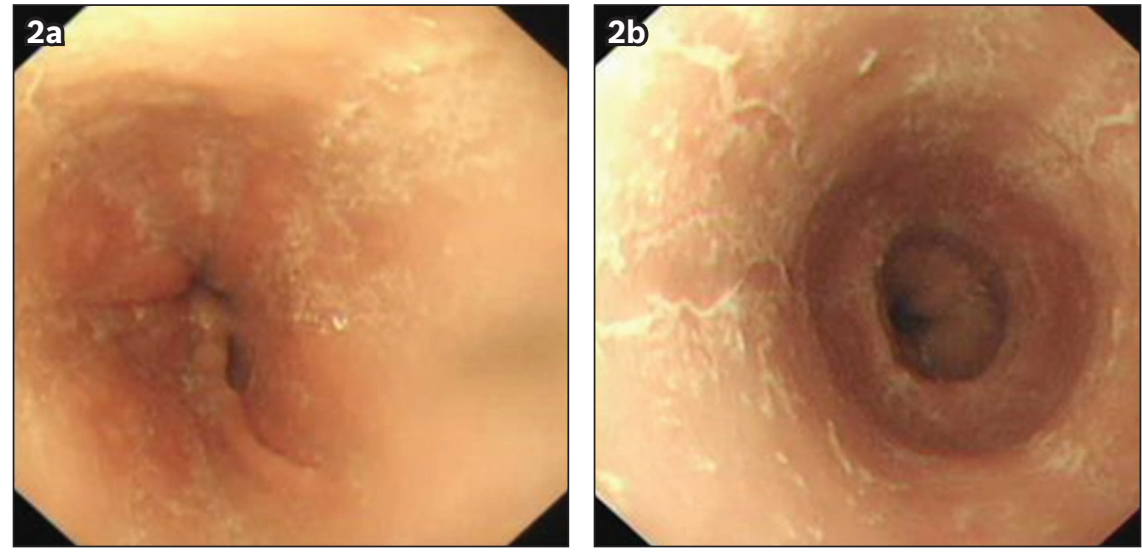

Fig. 2 Oesophagogastroduodenoscopy images show (a) inflammation and (b) slough in the oesophagus, characteristics that are suggestive of oesophagitis.

stratified squamous mucosa fragments with mild hyperplasia and $>15$ eosinophils/hpf in the oesophageal biopsy, characteristics that are in keeping with EoE. One child who had been diagnosed with EoE in the first review did not satisfy the criteria for EoE in the second review and was not included among the four patients. In the second review, the pathologist reported a mixed inflammatory infiltrate of lymphocytes, neutrophils and eosinophils that appeared with a combined score of up to 30/hpf, of which eosinophils only accounted for 7-8/hpf.

The histopathological features noted in all four children who were diagnosed with EoE during the second review included: (a) a mean eosinophil count $>15 / \mathrm{hpf}$; (b) degranulation of the eosinophils; (c) the presence of microabscess (collection $\geq 4$ eosinophils on the surface); (d) distribution of eosinophils predominantly in the superficial layers of the squamous epithelium of the oesophagus; and (e) patchy eosinophil distribution (Fig. 1).

The median age of symptom onset for the four children diagnosed with EoE in the second review was 9.5 (range 4.0-12.0) years. Of the four children, three were boys, three were Chinese and one was Caucasian. The main clinical presentation was abdominal pain, which was observed in the three older children (Patients 2, 3 \& 4). The abdominal pain, which occurred almost daily and was located mainly at the upper abdomen, did not resolve completely with anti-acid medications. Two of the four patients (Patients $2 \& 3$ ) also had heartburn and reported that the pain worsened when they were exposed to certain foods. Patient 4 was asymptomatic prior to endoscopy, but was already on a fluticasone inhaler and food avoidance for the items that he was previously proven to be sensitive to. In the youngest child, who was two years of age when he first presented to our institution, vomiting associated with feeding difficulties and poor weight gain was the main presenting complaint. Coincidentally, one of the children with persistent abdominal pain also had a duodenal ulcer that was related to a Helicobacter pylori infection (Patient 3). Among the four children, three had a personal history of atopy - two had been diagnosed with asthma or allergic rhinitis as toddlers (Patients $1 \& 2$ ), and one had multiple food allergies with elevated immunoglobulin E levels against various food substances (Patient 4). Patient 4 also had coeliac disease.

Endoscopy revealed oesophagitis (Fig. 2) in two children - one had erythema and sloughing at the mid-oesophagus (Patient 4), while the other had a granular and erythematous appearance of the oesophagus despite being on acid suppression therapy at that time (Patient 1). Although the remaining two children did not show typical macroscopic signs of EoE in the oesophagus when their biopsies were taken, they were started on acid suppression therapy, as erosive gastritis with duodenal ulcer was noted in one (Patient 3) and lax lower oesophageal sphincter with gastritis was noted in the other (Patient 2). Unfortunately, acid suppression alone did not relieve the symptoms in any of the four children. 
Thus, one child was also treated with swallowed fluticasone (Patient 4) and two with food avoidance (Patients $2 \& 3$ ); the addition of these treatments to acid suppression therapy resulted in symptom improvement.

\section{DISCUSSION}

The prevalence of EoE in Singapore, a predominantly Chinese country, is low compared to Western countries. ${ }^{(8,17)}$ To date, only a few studies have reported the prevalence of EoE in Chinese or Asians, most of which were conducted in adult Asian populations. ${ }^{(5,6)}$ The condition affects not only adult populations, but also paediatric populations.

Similar to other series on EoE, ${ }^{(17-19)}$ most of the patients with EoE in our study were male and often had atopic features. If a child with coeliac disease has persistent oesophageal symptoms, concomitant EoE should be considered, since it has been shown that there is an increased incidence of EoE among patients with coeliac disease. ${ }^{(20)}$ Concomitant EoE with coeliac disease was also observed in one of the patients in our study. However, findings on the association between coeliac disease and EoE have been controversial; a recent study, which analysed a large database of patients, did not find any association between the two conditions. ${ }^{(21)}$

Pathologists should actively look out for EoE when analysing oesophageal biopsy specimens. EoE should be suspected if the child has typical complaints of abdominal pain or recurrent vomiting, and a partial response to acid suppression therapy. Paediatric gastroenterologists have a role in alerting pathologists when sending such biopsy specimens for evaluation and should also ensure that at least 3-4 mucosal biopsy specimens are obtained from various segments of the oesophagus, including the proximal and distal oesophagus, so as to maximise the diagnostic yield.

Oesophageal eosinophilia is a histological finding that requires interpretation in the clinical context for which the biopsy specimen was obtained. The presence of eosinophils in the oesophageal epithelium is commonly seen in children with GERD, as noted in one of the patients in our study. Although this patient was diagnosed with GERD in the initial analysis/review, he was diagnosed with EoE at the second review.

The population of children in the present study did not have severe symptoms such as dysphagia or food impaction, although such symptoms have been described in the Western literature. ${ }^{(22,23)}$ This could be due to a genetic predisposition, whereby Chinese children may be less severely affected as compared to Western children. Another possible reason for this difference is that EoE was identified early and promptly treated in our study population. It is essential to initiate treatment early, as the progression of symptoms and complications, such as oesophageal strictures ${ }^{(24)}$ or fibrosis, can significantly impact the quality of life of the children.

In the four children with EoE in our study (three of whom were Chinese), the use of proton-pump inhibitors (PPIs) alone was insufficient for complete symptom resolution; additional intervention, such as food avoidance and swallowed steroids, was required. ${ }^{(25,26)}$ PPI-responsive oesophageal eosinophilia is an entity that is increasingly being recognised. Apart from being used to alleviate symptoms of GERD, PPIs may have a role in the regression of eosinophilic infiltrates. Swallowed steroids have been used in a few of our patients when therapy with PPIs and food avoidance failed to alleviate symptoms. However, the idea of swallowed steroids may not be easily accepted by our local population, as there may be considerable fear regarding the side effects of oral steroid use.

The present study was not without limitations. The sample size is small and more substantial conclusions could be made if larger sample sizes were involved. In addition, the retrospective nature of the study may have resulted in a reduced number of patients being included and information being missed out during data collection. Formal evaluation of dietary allergy testing was also not undertaken for all of the patients. Allergy testing could have provided interesting data with regard to food allergen triggers for EoE.

In conclusion, EoE is not common in Singapore, which has a predominantly Chinese population. Nonetheless, this condition exists, and family physicians and general paediatricians practising in Singapore should be aware of it. EoE should be suspected in children with typical complaints of reflux oesophagitis, particularly if they have a partial response to acid suppression therapy. The presence of atopy in the child or a family history of atopy would further raise the suspicion of EoE. Endoscopic evaluation and referral to a gastroenterologist is warranted in children with these characteristics. Paediatric gastroenterologists have a role in alerting pathologists when sending out biopsy specimens from such patients for review, and pathologists who receive such specimens should actively look out for signs indicative of EoE.

\section{ACKNOWLEDGEMENT}

We thank Dr Dimple Rajgor, National University Children's Medical Institute, National University Health System, Singapore, for her assistance in conducting literature research for this study, and for writing, editing, formatting, reviewing and submitting this manuscript for publication.

\section{REFERENCES}

1. Landres RT, Kuster GG, Strum WB. Eosinophilic esophagitis in a patient with vigorous achalasia. Gastroenterology 1978; 74:1298-1301.

2. Noel RJ, Putnam PE, Rothenberg ME. Eosinophilic esophagitis. N Engl J Med 2004; 351:940-1.

3. Straumann A, Simon HU. Eosinophilic esophagitis: escalating epidemiology? J Allergy Clin Immunol 2005; 115:418-9.

4. Prasad GA, Alexander JA, Schleck CD, et al. Epidemiology of eosinophilic esophagitis over three decades in Olmsted County, Minnesota. Clin Gastroenterol Hepatol 2009; 7:1055-61.

5. Joo MK, Park JJ, Kim SH, et al. Prevalence and endoscopic features of eosinophilic esophagitis in patients with esophageal or upper gastrointestinal symptoms. J Dig Dis 2012; 13:296-303.

6. Shi YN, Sun SJ, Xiong LS, et al. Prevalence, clinical manifestations and endoscopic features of eosinophilic esophagitis: a pathological review in China. J Dig Dis 2012; 13:304-9.

7. Al-Hussaini A, Semaan T, El Hag I. Eosinophilic esophagitis in a developing country: is it different from developed countries? Gastroenterol Res Pract 2013; 2013:526037.

8. Orenstein SR, Shalaby TM, Di Lorenzo C, et al. The spectrum of pediatric eosinophilic esophagitis beyond infancy: a clinical series of 30 children. 
Am J Gastroenterol 2000; 95:1422-30.

9. Arora AS, Yamazaki K. Eosinophilic esophagitis: asthma of the esophagus? Clin Gastroenterol Hepatol 2004; 2:523-30.

10. Steiner SJ, Gupta SK, Croffie JM, Fitzgerald JF. Correlation between number of eosinophils and reflux index on same day esophageal biopsy and 24 hour esophageal pH monitoring. Am J Gastroenterol 2004; 99:801-5.

11. Liacouras CA, Spergel JM, Ruchelli E, et al. Eosinophilic esophagitis: a 10-year experience in 381 children. Clin Gastroenterol Hepatol 2005 3:1198-206.

12. Furuta GT, Liacouras CA, Collins $\mathrm{MH}$, et al; First International Gastrointestinal Eosinophil Research Symposium (FIGERS) Subcommittees. Eosinophilic esophagitis in children and adults: a systematic review and consensus recommendations for diagnosis and treatment. Gastroenterology 2007; 133:1342-63.

13. Rodrigo S, Abboud G, Oh D, et al. High intraepithelial eosinophil counts in esophageal squamous epithelium are not specific for eosinophilic esophagitis in adults. Am J Gastroenterol 2008; 103:435-42.

14. Khan S, Orenstein SR, Di Lorenzo C, et al. Eosinophilic esophagitis: strictures, impaction, dysphagia. Dig Dis Sci 2003; 48:22-9.

15. Lim JR, Gupta SK, Croffie JM, et al. White specks in the esophageal mucosa: An endoscopic manifestation of non-reflux eosinophilic esophagitis in children. Gastrointest Endosc 2004; 59:835-8.

16. Liacouras CA, Furuta GT, Hirano I, et al. Eosinophilic esophagitis: updated consensus recommendations for children and adults. J Allergy Clin Immunol 2011; 128:3-20.e6.

17. Kapel RC, Miller JK, Torres C, et al. Eosinophilic esophagitis: a prevalent disease in the United States that affects all age groups. Gastroenterology 2008; 134:1316-21.

18. O'Donnell S, Kelly OB, Breslin N, et al. Eosinophilic oesophagitis: an Irish experience. Eur J Gastroenterol Hepatol 2011; 23:1116-21.

19. Arias Á, Lucendo AJ. Prevalence of eosinophilic oesophagitis in adult patients in a central region of Spain. Eur J Gastroenterol Hepatol 2013; 25:208-12.

20. Thompson JS, Lebwohl B, Reilly NR, et al. Increased incidence of eosinophilic esophagitis in children and adults with celiac disease. J Clin Gastroenterol 2012; 46:e6-e11.

21. Jensen ET, Eluri S, Lebwohl B, Genta RM, Dellon ES. Increased risk of esophageal eosinophilia and eosinophilic esophagitis in patients with active celiac disease on biopsy. Clin Gastroenterol Hepatol 2015; 13:1426-31.

22. Guz-Mark A, Zevit N, Rosenbach Y, et al. [Eosinophilic esophagitis--the experience in a tertiary pediatric center]. Harefuah 2011; 150:432-7, 492. Hebrew.

23. Vindigni C, Villanacci V, Marini $M$, et al. Eosinophilic esophagitis: an Italian experience. Rev Esp Enferm Dig 2010; 102:15-9.

24. Kim HP, Vance RB, Shaheen NJ, Dellon ES. The prevalence and diagnostic utility of endoscopic features of eosinophilic esophagitis: a meta-analysis. Clin Gastroenterol Hepatol 2012; 10:988-96.e5.

25. Vithayasai $N$, Jennuvat S, Lertsatit A. Eosinophilic gastrointestinal disease: analysis of sixteen cases from ten years experience in Thailand. J Med Assoc Thai 2011; 94 Suppl 3:S41-8.

26. Redd M, Schey R. Eosinophilic esophagitis: current treatment. Dig Dis Sci 2013; 58:613-20. 